\title{
EL PRINCIPIO PRO PERSONA EN EL ESTADO CONSTITUCIONAL Y DEMOCRÁTICO DE DERECHO
}

\author{
Pro persona principle in a constitutional and democratic state of law
}

\author{
Alma Rosa BAHENA VILLALOBOS
}

Sumario:

I. Introducción. II. La reforma constitucional de derechos humanos en México. III. La protección de los derechos fundamentales en un Estado Constitucional y Democrático de Derecho. IV. El principio pro persona. V. Conclusiones. VI. Fuentes de consulta.

Resumen: El principio pro persona es un criterio hermenéutico que rige al derecho en materia de derechos humanos que consiste en preferir la norma o criterio más amplio en la protección de derechos humanos y la norma o criterio que menos restrinja el goce de los mismos. El presente artículo analiza el principio pro persona en el marco de un Estado constitucional y democrático de derecho. Asimismo realiza una revisión de este principio tanto en el aspecto doctrinal como en su regulación constitucional y legal y en algunos criterios jurisdiccionales, tanto en el ámbito nacional como en el internacional.

Palabras clave: pro persona, derechos humanos.

Abstract: Pro persona principle is an overarching human rights interpretative procedure which implicates preferring the norm that better protects a human right or the one that less affects it. This article studies pro persona principle in a constitutional and democratic state of law. As well as develops a review in the doctrinal, constitutional and legal regulation and rights adjudication in the mexican and international scope.

Keywords: pro persona, human rights.

\section{INTRODUCCIÓN}

El principio pro persona es un criterio hermenéutico característico de los derechos humanos que consiste en aplicar el precepto jurídico o la interpretación más favorable cuando se trate del reconocimiento y goce de derechos, e inversamente, en la aplicación del precepto

\footnotetext{
1 Licenciada en derecho y Maestra en Derecho Constitucional por la Universidad Latina de América. Candidata a Doctora en Derecho por el Doctorado Interinstitucional en Derecho (DID) de la región Centro Occidente del país y académica de la Universidad Michoacana de San Nicolás de Hidalgo. Consejera ciudadana del Consejo de la Comisión Estatal de Derechos Humanos Michoacán y Especialista en medios alternos de solución de conflictos, Supremo Tribunal de Justicia del Estado de Michoacán de Ocampo.
} 
o interpretación más restrictiva cuando se intente afectar el acceso o goce de un derecho fundamental, en aras de estar siempre a favor de la persona.

El objetivo del presente artículo es analizar, dentro de un Estado constitucional y democrático de derecho, el papel toral que desempeñan los derechos fundamentales, comprendiendo que en este Estado tienen un rol preponderante los principios frente a las reglas. Y toda vez que el principio pro persona o de la protección más amplia de los derechos humanos, es uno de los mandatos constitucionales establecidos por el constituyente permanente en la reforma de junio de 2011, producto de la tenacidad de diversas organizaciones civiles y de académicos especialistas en materia de derechos humanos, es que este principio será abordado desde la doctrina, así como en su proceso de construcción normativa en nuestro país -que pasa por su interpretación por parte de las autoridades mexicanas- y en su desarrollo en el contexto internacional.

\section{LA REFORMA CONSTITUCIONAL DE DERECHOS HUMANOS EN MÉXICO}

\section{El nuevo paradigma constitucional en México}

Para hablar del nuevo paradigma constitucional en nuestro país es de referencia obligatoria el conjunto de reformas en materia de derechos humanos, publicadas el diez de junio del año dos mil once en el Diario Oficial de la Federación (D.O.F.), las cuales constituyen el surgimiento de un nuevo parangón de interpretación y aplicación de nuestra Constitución, por medio de las cuales se le reafirma como normativa, máxime cuando se trate de las disposiciones constitucionalmente establecidas especialmente en materia de derechos humanos.

De lo anteriormente expuesto, el reto sustancial que enfrentan todas las autoridades mexicanas -en tanto obligadas a promover, respetar, proteger y garantizar los derechos humanos ${ }^{2}$ consagrados tanto en la Constitución como en los tratados internacionales aprobados por el Estado mexicano ${ }^{3}$-, consiste primariamente, en conocer el corpus iuris, conformado tanto por normas de producción interna, como aquellas de producción externa,${ }^{4}$ que conforman el bloque de constitucionalidad. ${ }^{5}$ Este presupuesto es necesario para posteriormente estar en condiciones de interpretar y aplicar el nuevo sistema jurídico, que se integra por normas, enunciadas ya sea en forma de reglas o de principios, tales como: el principio pro persona ${ }^{6}$

2 Obligación establecida en el artículo $1^{\circ}$, párrafo tercero de la Constitución Política de los Estados Unidos Mexicanos y cuyos alcances los estipula la Suprema Corte de Justicia de la Nación en el expediente "Varios" 912/2010.

3 De acuerdo con los artículos 26 y 27 de la Convención de Viena sobre el Derecho de los Tratados, el Estado mexicano estableció su compromiso de cumplir con las obligaciones contraídas internacionalmente (pacta sunt servanda), así como de no invocar su derecho interno para evadirse de las mismas.

4 Ya sean tratados o instrumentos internacionales, no únicamente en materia de derechos humanos, sino también aquellos que aun siendo reguladores primordialmente de otra materia, contengan en sus textos derechos humanos.

5 Véase REQUEJO PAGÉS, Juan Luis, Sistemas normativos, constitución y ordenamiento. La constitución como norma sobre aplicación de normas, Madrid, Mac Graw-Hill, 1995, p. 12; AYALA CORAO, Carlos, "Las consecuencias de la jerarquía constitucional de los tratados relativos a derechos humanos y sus consecuencias", en MÉNDEZ SILVA, Ricardo (coord.), Derecho Internacional de los derechos humanos. Memoria del VII Congreso Iberoamericano de derecho constitucional, México, IIJ-UNAM, 2002.

6 Respecto del principio pro persona o pro homine, Cfr. CABALLERO OCHOA, José Luis, La incorporación de los tratados internacionales sobre derechos humanos en España y México, Porrúa, México, 2009, pp. 6263, 220 y ss., y 309-310; BAHENA VILLALOBOS, Alma Rosa, "La supremacía del principio pro homine en 
y el principio de interpretación conforme, ${ }^{7}$ contenidos ahora en el artículo $1^{\circ}$, párrafo segundo de la Constitución. Asimismo, con la ratificación de la Convención Americana sobre Derechos Humanos ${ }^{8}$ y con el reconocimiento de la competencia contenciosa de la Corte Interamericana de Derechos Humanos, ${ }^{9}$ el Estado mexicano ha adquirido el compromiso de acatar las decisiones de dicha Corte. ${ }^{10}$ tanto en los casos en que sea parte, como en aquellas resoluciones que emita para el resto de los países miembros ${ }^{11}$. Asimismo es a partir de la jurisprudencia emitida por la Corte Interamericana de Derechos Humanos (Cor IDH) ${ }^{12}$ en el Caso Almonacid Arellano Vs. Perú, que todas las autoridades judiciales deben realizar el control de convencionalidad, ${ }^{13}$ obligación reiterada por el Caso Rosendo Radilla Vs. México. ${ }^{14}$

Y consolidando este conjunto de compromisos internacionales, en el Caso Gelman Vs. Uruguay sobre supervisión de cumplimiento de sentencia que reafirmó la obligatoriedad de todas las autoridades de los Estados partes de acatar la "cosa juzgada internacional" o res iudicata, como la "cosa interpretada internacional" o res interpretata. ${ }^{15}$

Este deber se traduce en aplicar los tratados e instrumentos internacionales aprobados por México, siendo de interés especial aquellos con contenidos de derechos humanos, así como las sentencias e interpretaciones emitidas por los organismos internacionales de los que nuestro país sea parte, puesto que en materia de derechos humanos hemos asumido el compromiso de cumplir la Convención Americana sobre Derechos Humanos, así como las resoluciones que al efecto emita la Cor IDH, de tal forma que el Estado mexicano garantice los estándares internacionales de protección de los derechos humanos en su ámbito interno,

México", en Cuadernos de Derecho Constitucional. Revista de la Maestría en Derecho Constitucional de la Universidad Latina de América, vol. 1, no. 1, 2009, pp. 20-32.

7 Véase CABALLERO OCHOA, José Luis, ibídem, pp. 177 y ss.

${ }^{8}$ Ratificada por México el 2 de marzo de 1981 y depositado el instrumento el 24 de marzo del mismo año. El artículo 68 de la Convención Americana sobre Derechos Humanos (CIDH) dispone lo siguiente: "1. Los Estados Partes en la Convención se comprometen a cumplir la decisión de la Corte en todo caso en que sean partes..." Además del deber de los Estados Partes de adoptar las disposiciones de derecho interno, tanto legislativas como de cualquier otro carácter para hacer efectivos los derechos y libertades, establecido en el artículo 2 de la misma Convención.

9 Depositado el instrumento de aceptación el 16 de diciembre de 1998 ante la Secretaría General de la O.E.A., y publicado en el D.O.F., el 24 de febrero de 1999.

${ }^{10}$ Véase también el Expediente "Varios" 912/2010 y la Contradicción de tesis 293/2011, que se analiza infra, del Pleno de la Suprema Corte de Justicia de la Nación.

${ }^{11}$ Cfr. Voto razonado del Caso Cabrera García y Montiel Flores vs. México. Excepciones preliminares, Fondo, Reparaciones y Costas, párrafos 51-52 y 63: "El juez nacional, por consiguiente, debe aplicar la jurisprudencia convencional incluso la que se crea en aquellos asuntos donde no sea parte el Estado nacional al que pertenece, ya que lo que define la integración de la jurisprudencia de la Corte IDH es la interpretación que ese Tribunal Interamericano realiza del corpus juris interamericano con la finalidad de crear un estándar en la región sobre su aplicabilidad y efectividad". Así como expediente "Varios" 912/2010 del Pleno de la Suprema Corte de Justicia de la Nación (SCJN).

12 Órgano consultivo y jurisdiccional, intérprete y garante de la Convención Americana sobre Derechos Humanos de 1969, cuya entrada en vigor fue en 1978 e instalado el 3 de septiembre de 1979. Véase GARCíA RAMÍREZ, Sergio, Temas de la Jurisprudencia Interamericana sobre Derechos Humanos. Votos particulares, ITESO/UIA/UAG, México, 2005, pp. iii-vii; DIENHEIM BARRIGUETE, Cuauhtémoc M., DE, "La protección internacional de los derechos humanos", en FIX-ZAMUDIO, Héctor, et. al., Protección internacional de los Derechos Humanos, Argentina, Librería Editora Platense, p. 128.

${ }^{13}$ Vid. Expediente "Varios" 912/2010, pp. 30-37.

${ }^{14}$ Véase párrafo 339.

${ }^{15}$ Cfr. Voto razonado del Dr. Eduardo Ferrer Mac-Gregor Poisot, correspondiente a la resolución de la Corte Interamericana de 20 de marzo de 2013, sobre Supervisión de cumplimiento de sentencia del Caso Gelman vs. Uruguay, párrafos 22 y ss. 
además de ajustarse a los más altos estándares establecidos en cada resolución o interpretación emitidas por dicha Corte, y con base en el principio de subsidiariedad, los jueces locales se convierten a su vez en jueces interamericanos, formando parte de una gran red de protección de los derechos humanos.

\section{LA PROTECCIÓN DE LOS DERECHOS FUNDAMENTALES EN UN ESTADO CONSTITUCIONAL Y DEMOCRÁTICO DE DERECHO}

\section{El Estado constitucional y democrático de derecho y los derechos fundamentales}

Después de la Segunda Guerra Mundial, el concierto internacional generó consenso sobre la necesidad de generar alternativas que promovieran y garantizaran el respeto a los derechos humanos, de tal forma que las violaciones dejaran de ser tópicos de incumbencia exclusiva de cada país, por lo que el instrumento aglutinante de los esfuerzos de los Estados participantes de este cambio de paradigma internacional de los derechos humanos se tradujo en la Declaración Universal de los Derechos Humanos de 1948, dando comienzo al llamado proceso de "internacionalización de los derechos humanos". ${ }^{16}$ Con el transcurso de las décadas, el reconocimiento, desarrollo y especialización de los derechos fundamentales se ha reforzado tanto desde el Derecho Constitucional ${ }^{17}$ como del Derecho Internacional Público. ${ }^{18}$

Consecuentemente el Estado ha ido evolucionando, siendo hoy en día un modelo el Estado constitucional de derecho, ${ }^{19}$ cuyos avances más importantes podrían resumirse en que por el hecho de que los enunciados normativos sean vigentes ya no resultan suficientes para ser válidos, puesto que es necesario que superen el tamiz de la función sustancial. ${ }^{20}$ En este sentido es que Ferrajoli afirma que el paradigma del modelo garantista o del Estado constitucional de derecho implica un doble sometimiento del derecho al mismo derecho, en los aspectos tanto formales (vigencia, signos, legitimación formal o racionalidad formal), como sustanciales (validez, significado, legitimación sustancial o racionalidad sustancial), ${ }^{21}$ resultando que los derechos fundamentales se encuentran impregnados de estas últimas cualidades sustanciales.

En consecuencia, la garantía sustancial puede traducirse en que brinda protección contramayoritaria, aún en situaciones de unanimidad, es decir, protege de una posible tiranía de la mayoría a aquellas minorías cuyos derechos pretendieran ser o resultaran vulnerados. En materia de derechos fundamentales es lo que Ferrajoli denomina el respeto a la esfera de lo indecidible ${ }^{22}$ o lo que para Peter Häberle constituye la garantía del contenido esencial de

\footnotetext{
$\overline{16}$ DIENHEIM BARRIGUETE, Cuauhtémoc, DE, “Derechos Humanos y Democracia: principios éticos de un nuevo orden jurídico mundial”, en CABALLERO, José Luis (coord.), La Declaración Universal de los Derechos Humanos. Reflexiones en torno a su 60 aniversario, México, Porrúa, 2009, p. 46.

${ }^{17}$ A través de la rama del Derecho Constitucional de los Derechos Humanos. Cfr. AYALA CORAO, Carlos, Op. Cit., nota 5, p. 37.

${ }^{18}$ Desde el llamado Derecho Internacional de los Derechos Humanos. Idem.

${ }^{19} \mathrm{El}$ cual ha recibido diversas denominaciones -con diversos matices pero coincidiendo en la esencia respecto del respeto y garantía de los derechos fundamentales-, tales como: Garantista (Ferrajoli), Neoconstitucional (Prieto Sanchís, Comanducci, Barberis), Constitucional y Democrático de Derecho (Häberle).

${ }^{20}$ FERRAJOLI, Luigi, Derechos y Garantías. La ley del más débil, Madrid, Trotta, 2004, pp. 18 y ss.

${ }^{21}$ Ibidem, p. 22.

${ }^{22}$ Ibidem, p. 24. 
los derechos fundamentales ${ }^{23} \mathrm{y}$ cuyo núcleo no podría verse reducido o afectado puesto que implicaría el vaciamiento de tal derecho fundamental. Asimismo, Häberle postula que el ideal de organización político-social es el Estado constitucional y democrático de derecho, cuyos elementos constitutivos son:

la dignidad humana como premisa, realizada a partir de la cultura de un pueblo y de los derechos universales de la humanidad, vividos desde la individualidad de ese pueblo, que encuentran su identidad en tradiciones y experiencias históricas, y sus esperanzas en los deseos y la voluntad creadora hacia el futuro; el principio de soberanía popular, pero no entendida como competencia para la arbitrariedad ni como magnitud mística por encima de los ciudadanos, sino como fórmula que caracteriza la unión renovada constantemente en la voluntad y en la responsabilidad pública; la Constitución como contrato en cuyo marco son posibles y necesarios fines educativos y valores orientadores; el principio de la división de poderes tanto en sentido estricto relativo al Estado, como en el sentido amplio del pluralismo; los principios del Estado de derecho y el Estado social, lo mismo que el principio del Estado de Cultura (kulturstaat) abierto; las garantías de los derechos fundamentales; la independencia de la jurisdicción y algunos otros más que deben estar incorporados en una democracia ciudadana basada en el principio del pluralismo. ${ }^{24}$

Para Robert Alexy, los derechos fundamentales son uno de los seis principios esenciales que constituyen al Estado constitucional democrático, al igual que la dignidad humana, la libertad, la igualdad, la estructura y los fines del Estado de derecho, democrático y social. ${ }^{25}$

Por otra parte, para Prieto Sanchís los elementos de un Estado constitucional pueden resumirse en los siguientes: a) la normatividad constitucional o fuerza vinculante, b) la supremacía constitucional, c) la eficacia o aplicación directa de la Constitución, d) la garantía judicial, e) la rigidez constitucional y, f) un abundante contenido normativo que puede traducirse en los derechos fundamentales, enunciados ya sea como principios, derechos propiamente o directrices. Asimismo distingue que en el modelo neoconstitucional se postula la preponderancia de los principios frente a las reglas, la ponderación más que la subsunción, la omnipresencia constitucional o desbordamiento constitucional ${ }^{26}$ en todas las áreas jurídicas en vez de los espacios de libertad de decisión legislativa o reglamentaria, la prelación de la decisión judicial frente a la autonomía del legislador ordinario y la convivencia de un conjunto de valores que pudieran aparecer en dado momento como contradictorios en lugar de una ideología homogénea. ${ }^{27}$

\footnotetext{
${ }^{23}$ HÄBERLE, Peter, La garantía del contenido esencial de los derechos fundamentales en la Ley Fundamental de Bonn, trad. de Joaquín Brage Camazano, Madrid, Dykinson, 2003, p. 63.

${ }^{24}$ HÄBERLE, Peter, El Estado Constitucional, México, UNAM, 2003, pp. 1 y 2.

${ }^{25}$ ALEXY, Robert, “Derechos fundamentales y Estado constitucional democrático”, en CARBONELL, Miguel (ed.), Neoconstitucionalismo(s), $2^{\text {a }}$ ed., Madrid, Trotta, 2005, p. 31.

${ }^{26} \mathrm{O}$ también denominado por Häberle como principio de irradiación.

27 PRIETO SANCHÍS, Luis, Justicia constitucional y derechos fundamentales, Madrid, Trotta, 2003, pp. 101 y ss.
} 


\section{Los derechos fundamentales y la democracia constitucional}

En la actualidad, la democracia no puede ser simplemente concebida como el gobierno de la mayoría puesto que no sólo debe ser referida al aspecto cuantitativo como al cualitativo. ${ }^{28}$ Para los representantes de la Escuela de Turín, Norberto Bobbio, en voz de su discípulo Michelangelo Bovero, los retos que enfrenta la democracia son: el principio de igualdad política, el igual valor y peso de los votos, el pluralismo informativo, el pluralismo político, el principio de mayoría, sin dejar de lado el último principio que es el respeto de los derechos de las minorías. ${ }^{29}$ Asimismo establece que los ideales de los valores universales son: la democracia, los derechos humanos y la paz. ${ }^{30}$

Para Ferrajoli, el constitucionalismo es el resultado de la evolución del concepto original de democracia, puesto que ésta ya no se refiere a la toma de decisiones por mayoría, sino a una democracia sustancial o constitucional, en la que la soberanía popular no es ilimitada, sino que se encuentra irreductiblemente vinculada al respeto de los derechos fundamentales y de sus garantías. De modo que "estos derechos... no son solamente límites a la democracia política. Son, además, la sustancia democrática..." ${ }^{31}$ En consecuencia, el constitucionalismo condensa los avances sustanciales logrados a partir de la superación de los fascismos cuyos triunfos políticos fueron alcanzados por las vías formalmente democráticas y posteriormente se tornaron en la antítesis de la democracia. De esta manera es que se explica el nexo estructural entre el constitucionalismo y la democracia, en donde las garantías constitucionales de los derechos humanos son a la vez garantías de la democracia misma, ${ }^{32}$ por lo que el control jurisdiccional de la constitucionalidad constituye un elemento tan relevante que da sentido y legitimidad democrática al juzgador en cuanto que garantiza la plena eficacia de los derechos fundamentales, no solo de aquellos estipulados ex constitutionae, sino también de aquellos incorporados al sistema jurídico nacional de origen internacional, de modo que se presenta un ordenamiento nacional, complementario o dual: compuesto tanto por normas de producción interna como externa ${ }^{33}$ para crear un bloque de constitucionalidad. ${ }^{34}$

\section{EL PRINCIPIO PRO PERSONA}

\section{Definición}

De acuerdo con Martín Ábrego y Christian Courtis, el principio pro persona o pro homine consiste en "un criterio hermenéutico que informa todo el derecho de los derechos humanos, en virtud del cual se debe acudir a la norma más amplia, o a la interpretación más extensiva, cuando se trata de reconocer derechos protegidos e, inversamente, a la norma o a la interpretación más restringida cuando se trata de establecer restricciones permanentes al ejercicio de

\footnotetext{
${ }^{28}$ ALFONZO JIMÉNEZ, Armando, Acerca del Estado. Breves reflexiones sobre política y derecho, México, 2008, p. 35 .

29 BOVERO, Michelangelo, Los desafíos de la democracia, México, Ubijus, 2013, pp. 35-37.

${ }^{30}$ Ibidem, pp. 42 y 43

${ }^{31}$ FERRAJOLI, Luigi, “Democracia constitucional y derechos fundamentales. La rigidez de la Constitución y sus garantías", en FERRAJOLI, Luigi et al., La teoría del derecho en el paradigma constitucional, México, CAJICA, 2009, p. 73.

32 Ibidem, p. 74.

${ }^{33}$ REQUEJO PAGÉS, Juan Luis, Op. Cit., nota 5, p. 12.

${ }^{34}$ AYALA CORAO, Carlos, Op. Cit., nota 5, p. 53. 
los derechos de suspensión extraordinaria. El principio coincide con el rasgo fundamental de derecho de los derechos humanos, esto es, estar siempre a favor del hombre. ${ }^{35} \mathrm{Es}$ con base en la anterior definición que podemos distinguir que el principio pro persona tiene una doble dimensión, en primer lugar dispone el deber de aplicar la norma o la interpretación más favorable a la persona en el ejercicio de un derecho, y en segundo, el deber de acudir a la norma o interpretación que menos requisitos o restricciones imponga para el acceso o goce de un derecho. Y de acuerdo con Bidart Campos, los tratados internacionales sobre derechos humanos generalmente garantizan de una mejor manera o "dejan a salvo los mejores derechos que pueden surgir del derecho interno de los Estados que se hacen parte de ellos", ${ }^{36}$ y como ejemplo podemos mencionar al artículo $53^{37}$ de la Convención de Viena sobre el Derecho de los Tratados, que pese a no ser un instrumento internacional especializado en derechos humanos, sino más bien un tratado-marco, fija la obligación de los Estados contratantes de asumir el principio o postura pro persona, y para algunos juristas como Carlos Montemayor, "este artículo es lo único que limita en Derecho Internacional" a la "autonomía de la voluntad soberana de los Estados", y por tanto, los "derechos (fundamentales) deben incluirse dentro de las obligaciones no derogables por tratado". ${ }^{8}$

\section{Configuración constitucional y legal}

Previamente a la constitucionalización del principio pro persona, éste fue regulado en la Ley Federal para Prevenir y Eliminar la Discriminación en sus artículos $6{ }^{39}$ y $7,{ }^{40}$ de manera que en terminología de K. Hesse, éste ya ha sido "concretizado", propiciando un sinnúmero de beneficios, tales como: la inevitable e ineludible aplicación de la norma que más favorezca al individuo por parte de todas las autoridades al estar previsto actualmente en la Constitución; el tan esperado reconocimiento de los tratados de derechos humanos como norma

\footnotetext{
${ }^{35}$ Principio definido por Martín Abrego y Christian Courtis, en La aplicación de los tratados internacionales sobre derechos humanos por los tribunales locales, Ed. del Puerto, p. 163 y citado por los licenciados Hilario Bárcenas Chávez, Jesús Antonio Nazar Sevilla y Jean Claude Tron Petit, Magdos. del Cuarto Tribunal Colegiado en Materia Administrativa del Primer Circuito, dentro de la sentencia de Revisión de Amparo 799/2003, Considerando octavo, p. 125. En dicha resolución se controvierten derechos sociales como el derecho a la salud, a la seguridad social, a la permanencia en el empleo, así como actos discriminatorios en contra de un militar con VIH y su familia.

${ }^{36}$ BIDART CAMPOS, Germán J., El derecho de la Constitución y su fuerza normativa, México, IIJ-UNAM, 2003, p. 460.

37 "Artículo 53. Tratados que estén en oposición con una norma imperativa de derecho internacional general (ius cogens). Es nulo todo tratado que, en el momento de su celebración, esté en oposición con una norma imperativa de derecho internacional general. Para los efectos de la presente Convención una norma imperativa de derecho internacional general es una norma aceptada y reconocida por la comunidad internacional de Estados en su conjunto como norma que no admite acuerdo en contrario y que sólo puede ser modificada por una norma ulterior de derecho internacional que tenga el mismo carácter." Y una norma imperativa de derecho internacional es obviamente la relativa a la protección de los derechos humanos.

${ }^{38}$ MONTEMAYOR ROMO DE VIVAR, Carlos, La unificación conceptual de los derechos humanos, México, Porrúa-Facultad de Derecho de la UNAM, 2002, pp. 46 y 47.

39 "Artículo 6.- La interpretación del contenido de esta Ley, así como la actuación de las autoridades federales será congruente con los instrumentos internacionales aplicables en materia de discriminación de los que México sea parte, así como las recomendaciones y resoluciones adoptadas por los organismos multilaterales y regionales y demás legislación aplicable."

40 "Artículo 7.- Para los efectos del artículo anterior, cuando se presenten diferentes interpretaciones, se deberá preferir aquella que proteja con mayor eficacia a las personas o a los grupos que sean afectados por conductas discriminatorias."
} 
suprema en cuanto brinde derechos más favorables ${ }^{41}$ por parte de todas las autoridades, y el necesario abandono de la tesis emitida por la $\mathrm{SCJN}^{42}$ sobre la jerarquía de la Constitución, tratados internacionales y leyes federales que únicamente sembró incertidumbre y no abonó en claridad a la interpretación derivada del artículo 133, el cual, fue calificado de "oscuro, incongruente y dislocador de nuestro sistema”, entre otras cuestiones, por cuanto no establece con exactitud los órdenes jerárquicos ${ }^{43}$ ni la garantía del respeto a los tratados internacionales ${ }^{44}$ sobre derechos humanos y como consecuencia, se careció de mecanismos que evitaran que el Estado mexicano incurriera en responsabilidades internacionales.

Y fue precisamente que dentro del conjunto de reformas de junio de dos mil once que el principio pro persona fue incorporado a la Constitución en el artículo primero, párrafo segundo, para quedar enunciado en los siguientes términos:

Artículo $1^{\circ}$. En los Estados Unidos Mexicanos todas las personas gozarán de los derechos humanos reconocidos en esta Constitución y en los tratados internacionales de los que el Estado Mexicano sea parte, así como de las garantías para su protección, cuyo ejercicio no podrá restringirse ni suspenderse, salvo en los casos y bajo las condiciones que esta Constitución establece.

Las normas relativas a los derechos humanos se interpretarán de conformidad con esta Constitución y con los tratados internacionales de la materia favoreciendo en todo tiempo a las personas la protección más amplia. ${ }^{45}$

Es propicio hacer mención de que dichas reformas son el resultado de un intenso y largo proceso de trabajo de diversas organizaciones de la sociedad civil y del esfuerzo de académicos de todo el país quienes ejercieron presión en nuestros legisladores para ver cristalizados algunos de los avances en materia de derechos humanos que hoy en día están reconocidos en nuestra Constitución, ${ }^{46}$ dentro de los cuales se encuentra precisamente el principio pro persona. ${ }^{47}$

\footnotetext{
${ }^{41}$ De donde se interpreta que el derecho internacional contemporáneo tiene prelación sobre el derecho interno, ya que así lo contempla el artículo 27 de la Convención de Viena, del cual se desprende que el derecho interno no puede alegarse para incumplir con los tratados internacionales.

${ }^{42}$ Tesis P. LXXVII/99, Semanario Judicial de la Federación y su Gaceta, Novena Época, t. X, noviembre de 1999, p. 46, bajo el rubro "TRATADOS INTERNACIONALES. SE UBICAN JERÁRQUICAMENTE POR ENCIMA DE LAS LEYES FEDERALES Y EN UN SEGUNDO PLANO RESPECTO DE LA CONSTITUCIÓN FEDERAL".

43 CABALLERO OCHOA, José Luis, "Una vuelta a los principios sobre derechos humanos en la Constitución Mexicana. Algunas pistas de reflexión a la luz del Derecho Comparado", en ORTIZ AHLF, Loretta et. al., Ensayos en torno a una propuesta de reforma constitucional en materia de política exterior y de derechos humanos, México, Porrúa-Universidad Iberoamericana, 2004, p. 43.

${ }^{44}$ Que como ya se indicó supra, estos mismos se pronuncian a favor del derecho que más beneficie a la persona.

${ }^{45}$ Las cursivas son añadidas.

${ }^{46}$ Cfr. Propuesta de reforma constitucional en materia de derechos humanos, elaborada por las organizaciones de la sociedad civil y por académicas y académicos especialistas en derechos humanos, México, 2008 y disponible en: http://www.sumatealareformaendh.org.mx

47 Ibidem, pp. 18-20.
} 


\section{El principio pro persona en tratados y resoluciones internacionales}

En diversos tratados e instrumentos internacionales que México ha adoptado y que por tanto, son obligatorios, se encuentra previsto este principio, que de manera enunciativa, y no limitativa, cito:

La Declaración Universal de los Derechos Humanos en su preámbulo. ${ }^{48}$

Asimismo en el artículo 30 de dicha Declaración se afirma que: "Nada en esta Declaración podrá interpretarse en el sentido de que confiere derecho alguno al Estado, a un grupo o a una persona, para emprender y desarrollar actividades o realizar actos tendientes a la supresión de cualquiera de los derechos y libertades proclamados en esta Declaración."

Igualmente se contiene en el artículo 29 de la Convención Americana sobre Derechos $\mathrm{Hu}$ manos ${ }^{49}$ y en el Pacto Internacional de los Derechos Civiles y Políticos, en cuyo artículo 2.2. manifiesta que los Estados parte se comprometen a adoptar todas las medidas necesarias para hacer efectivos los derechos del Pacto y que:

5.1. Ninguna disposición del presente Pacto podrá ser interpretada en el sentido de conceder derecho alguno a un Estado, grupo o individuo para emprender actividades o realizar actos encaminados a la destrucción de cualquiera de los derechos y libertades reconocidos en el Pacto o a su limitación en mayor medida que la prevista en él. 5.2. No podrá admitirse restricción o menoscabo de ninguno de los derechos humanos fundamentales reconocidos o vigentes en un Estado Parte en virtud de leyes, convenciones, reglamentos o costumbres, so pretexto de que el presente Pacto no los reconoce o los reconoce en menor grado.

El Protocolo Adicional a la Convención Americana sobre Derechos Humanos en materia de Derechos Económicos, Sociales y Culturales o "Protocolo de San Salvador", ratificado el 8 de

\footnotetext{
$\overline{48}$...Considerando que los pueblos de las Naciones Unidas han reafirmado en la Carta su fe en los derechos fundamentales del hombre, en la dignidad y el valor de la persona humana y en la igualdad de derechos de hombres y mujeres, y se han declarado resueltos a promover el progreso social y a elevar el nivel de vida dentro de un concepto más amplio de la libertad... Considerando que los Estados Miembros se han comprometido a asegurar, en cooperación con la Organización de las Naciones Unidas, el respeto universal y efectivo a los derechos y libertades fundamentales del hombre, y Considerando que una concepción común de estos derechos y libertades es de la mayor importancia para el pleno cumplimiento de dicho compromiso.

${ }^{49}$ Artículo 29. Normas de Interpretación. Ninguna disposición de la presente Convención puede ser interpretada en el sentido de... b) limitar el goce y ejercicio de cualquier derecho o libertad que pueda estar reconocido de acuerdo con las leyes de cualquiera de los Estados Partes o de acuerdo con otra convención en que sea parte uno de dichos Estados...
} 
marzo de 1996, también lo contempla en su artículo $4,{ }^{50}$ al igual que el Pacto Internacional de Derechos Económicos, Sociales y Culturales (PIDESC) en su artículo 5.1..$^{11}$

De lo anterior es posible apreciar que de todos estos instrumentos aprobados por nuestro país, y que son Ley Suprema de la Unión de acuerdo con el artículo 133 constitucional, ${ }^{52}$ se desprende que a partir de las reformas en derechos humanos de junio de 2011 ha sido muy clara la intención del Constituyente Permanente de decretar superado el criterio de la SCJN ${ }^{53}$ sobre la jerarquía infraconstitucional de los tratados internacionales ${ }^{54}$ con la reforma al artículo $1^{\circ}$, en particular de los que contengan disposiciones sobre derechos humanos. Asimismo mandata la aplicabilidad de los principios pro persona y de interpretación conforme. Y de acuerdo con Seara Vázquez, "cuando los tratados no se pueden aplicar en el orden interno por ser contrarios a la constitución, esta situación es irrelevante para el derecho internacional, y el estado es responsable por la no aplicación de esa obligación internacional". ${ }^{55} \mathrm{Y}$ atentos a Antonio Cançado "la primacía es de la norma más favorable a las víctimas, sea ella norma de derecho internacional o de derecho interno. (Ambas) interactúan en beneficio de los seres protegidos" ${ }^{56}$

Por otra parte, derivado de un estudio de derecho comparado de varios países latinoamericanos, ${ }^{57}$ es posible apreciar la tendencia al reconocimiento supraconstitucional o constitucional de los tratados internacionales sobre derechos humanos en donde algunos países han implementado interpretaciones progresistas y acordes a los parámetros internacionales en esta materia, al adoptar como un bloque integral a la Constitución y a los tratados internacionales, el cual se caracteriza por la función complementaria de una y otros, y en caso de contradicción entre ellos se considera el precepto o interpretación suprema, aquel que brinde mayor protección a los derechos humanos. Para ejemplificar lo anterior, considero valioso referir el caso de Costa Rica y su compromiso indeclinable a favor del principio pro persona, ya que en su artículo 7 constitucional se establece el nivel supralegal e infraconstitucional de los "tratados públicos, los convenios internacionales y los concorda-

\footnotetext{
${ }^{50}$ Artículo 4. No Admisión de Restricciones. No podrá restringirse o menoscabarse ninguno de los derechos reconocidos o vigentes en un Estado en virtud de su legislación interna o de convenciones internacionales, a pretexto de que el presente Protocolo no los reconoce o los reconoce en menor grado.

51 Ninguna disposición del presente Pacto podrá ser interpretada en el sentido de reconocer derecho alguno a un Estado, grupo o individuo para emprender actividades o realizar actos encaminados a la destrucción de cualquiera de los derechos o libertades reconocidos en el Pacto, o a su limitación en medida mayor que la prevista en él. 2. No podrá admitirse restricción o menoscabo de ninguno de los derechos humanos fundamentales reconocidos o vigentes en un país en virtud de leyes, convenciones, reglamentos o costumbres, a pretexto de que el presente Pacto no los reconoce o los reconoce en menor grado.

${ }^{52}$ Artículo 133. Esta Constitución, las leyes del Congreso de la Unión que emanen de ella y todos los Tratados que estén de acuerdo con la misma, celebrados y que se celebren por el Presidente de la República, con aprobación del Senado, serán la Ley Suprema de toda la Unión. Los jueces de cada Estado se arreglarán a dicha Constitución, leyes y tratados, a pesar de las disposiciones en contrario que pueda haber en las Constituciones o leyes de los Estados.

${ }^{53}$ En la sentencia del Amparo en Revisión 1475/98 del Sindicato Nacional de Controladores del Tránsito Aéreo.

54 Dicho criterio era poco progresista al subordinar expresamente los tratados internacionales a la Constitución de forma incondicional, sin distinguir entre instrumentos internacionales sobre derechos humanos o de derecho internacional privado, por citar un ejemplo.

${ }^{55}$ Citada por el Dr. Jorge Ulises Carmona Tinoco en el ensayo sobre el “Artículo 133" de la Constitución mexicana, página 33 .

56 Idem.

57 Tales como Guatemala, Venezuela, Colombia, Argentina y el caso particular de Costa Rica. Cfr. BAHENA VILLALOBOS, Alma Rosa, Op. Cit., nota 6, pp. 27 y ss.
} 
tos..." ${ }^{88}$ y sin embargo en virtud de la resolución judicial $3435-92^{59}$ y su aclaración $5759-93$, se ha interpretado que respecto de tratados internacionales en materia de derechos humanos, éstos tendrán prelación incluso frente a la Constitución, en la medida en que consagren más amplios derechos a las personas. ${ }^{60}$

Y siguiendo al Dr. Jorge Ulises Carmona Tinoco es importante mencionar que los instrumentos internacionales sobre derechos humanos cuentan con "ciertas especificidades que vienen dadas por el carácter de instrumentos de protección de tales derechos a favor de los individuos", ${ }^{61}$ criterio que ha sido sostenido por la misma Corte Interamericana en las Opiniones Consultivas OC-1/82, ${ }^{62}$ dentro de su párrafo 24 y en la $O C-2 / 82,{ }^{63}$ en el párrafo 29 , de donde se desprende que los Estados tienen la obligación de respetar los tratados internacionales de derechos humanos y proteger a cualquier individuo que se encuentre bajo su jurisdicción.

Asimismo y con fundamento en los artículos 27.1 y 31.1 de la Convención de Viena sobre el Derecho de los Tratado de 1969, el Estado mexicano se compromete a no invocar su derecho interno como justificación para no dar cumplimiento a los tratados que celebre, y de igual manera reconoce que la interpretación de los tratados en los que sea parte, será de buena fe y atendiendo a los objetivos y fines de cada uno. De ahí que exista la obligación del Estado mexicano de cumplir con sus compromisos asumidos ante la comunidad internacional so pena de ser responsable y sancionado en consecuencia. ${ }^{64}$

Asimismo la Cor IDH, ha aplicado el principio pro persona en diversas sentencias como en el Caso Ricardo Baena y otros Vs. Panamá, ${ }^{65}$ interpretando que dentro del procedimiento de petición o comunicación de la violación de un derecho contenido en la Convención, la Comisión deberá aplicar el principio pro persona, frente a la opción que establecen los artículos 50 y 51 de dicha Convención, ya sea presentando la demanda a la Corte por no haberse

\footnotetext{
${ }_{58}$ Cfr. Constitución Política de la República de Costa Rica, en http://www.constitution.org/cons/costaric.htm.

59 ARMIJO, Gilbert, La Tutela Supraconstitucional de los Derechos Humanos en Costa Rica, en http:www.scielo.cl/scielo.php?script=sci_arttextépid=S0718-00122003000100005\&lng=en\& nrm=i, este artículo "analiza la posición de los derechos fundamentales y la recepción de los derechos humanos en el ordenamiento jurídico de Costa Rica, considerando la eficacia de los instrumentos internacionales sobre la materia y la jurisprudencia de la Comisión y la Corte Interamericana de Derechos Humanos. El artículo analiza especialmente la jurisprudencia de la Sala Constitucional de la Corte Suprema de Costa Rica.
}

${ }^{60}$ AYALA CORAO, Carlos, Op. Cit., nota 5.

${ }^{61}$ Ponencia publicada en la obra MÉNDEZ SILVA, Ricardo (coord.), Op. Cit., nota 5.

${ }^{62}$ Opinión consultiva solicitada por el Perú el 24 de septiembre de 1982, mediante la cual la Corte resuelve que su competencia consultiva "puede ejercerse, en general, sobre toda disposición, concerniente a la protección de derechos humanos, de cualquier tratado internacional aplicable en los Estados americanos..."; de igual forma manifiesta que "podrá abstenerse de responder una consulta si aprecia que, en las circunstancias del caso, la petición excede de los límites de su función consultiva... ya sea porque el trámite de la solicitud pueda conducir a alterar o a debilitar, en perjuicio del ser humano, el régimen previsto por la Convención; ya sea por otra razón análoga." http://www.acnur.org/biblioteca/pdf/1263.pdf

${ }^{63}$ Que versa sobre el efecto de las reservas a la entrada en vigor de la Convención Americana de Derechos Humanos (artículos 74 y 75), emitida el 24 de septiembre de 1982, siendo Presidente de la Corte Interamericana, Carlos Roberto Reina, concluyendo por unanimidad que la Convención tiene vigor en un Estado que la ratifique o se adhiera a ella, con o sin reservas, a partir de la fecha de depósito del instrumento de ratificación o adhesión, según corresponda. Vid. http://corteidh.or.cr/docs/opiniones/seriea_02_esp.pdf.

${ }^{64}$ Como actualmente lo ha sido por los casos Castañeda Gütman, González y otras, Radilla Pacheco, Fernández Ortega y otros, Rosendo Cantú y otra, Cabrera García y Montiel Flores y García Cruz y Sánchez Silvestre en los que la Corte Interamericana responsabiliza y condena al Estado mexicano.

${ }^{65}$ Cfr. Cor IDH, Caso Baena Ricardo Vs Panamá. Fondo, Reparaciones y Costas. Sentencia de 2 de febrero de 2001, Serie C, No. 72, párr. 189. 
solucionado el asunto, o bien, mediante la emisión del informe que contenga sus opiniones, recomendaciones y conclusiones en el que deberá establecer un plazo razonable para que el Estado le dé cumplimiento. Una vez finalizado el plazo, la Comisión decidirá si publica o no el informe. Dicho criterio fue posteriormente citado en casos como el Herrera Ulloa Vs. Costa Rica, y Ricardo Canese Vs. Paraguay. De igual manera, fue nuevamente aplicado en el Caso de la "Masacre de Mapiripán" Vs. Colombia, ${ }^{66}$ estableciendo la interpretación evolutiva de los tratados de derechos humanos, ${ }^{67}$ de conformidad con lo dispuesto en la Convención Americana -artículo 29- y la Convención de Viena sobre el Derecho de los Tratados, ${ }^{68} \mathrm{de}$ modo que la Corte resolvió que deberá aplicarse la interpretación más favorable. ${ }^{69}$

Igualmente en el Caso Dacosta Cadogán Vs. Barbados, ${ }^{70}$ la Corte Interamericana se pronunció respecto de la pena de muerte, refiriendo que en su ejecución deberá aplicarse el principio pro persona, ${ }^{71}$ de manera que su imposición deberá limitarse rigurosamente con la finalidad de que progresivamente se logre su eliminación..$^{72}$ También fue refrendado en el Caso Sebastián Furlán, ${ }^{73}$ quien acusado de cometer un delito cuando el Código Civil de Argentina reconocía como infantes a todos aquellos menores de 21 años, ${ }^{74}$ la Corte Interamericana le reconoce su calidad de menor de edad, pese a que su propia jurisprudencia reconocía como menores a las personas que no hubiesen cumplido 18 años, ${ }^{75}$ con fundamento en el principio pro persona.

De lo anterior podemos comprobar cómo ha permeado el principio pro persona en los diversos sistemas jurídicos sin importar su fuente, ya sea que provenga de un criterio inter-

${ }^{66}$ Cor IDH, Caso de la “Masacre de Mapiripán” Vs. Colombia. Fondo, Reparaciones y Costas. Sentencia de 15 de septiembre de 2005. Serie C. No. 134, párrafo 106.

${ }^{67}$ Cfr. European Court of Human Rights, Tyrer v. The United Kingdom, judgment of 25 April 1978, Series A no. 26, párr. 31.

${ }^{68}$ Cfr. El Derecho a la Información sobre la Asistencia Consular en el Marco de las Garantías del Debido Proceso Legal. Opinión Consultiva OC-16/99 de 1 de octubre de 1999. Serie A No. 16, párr. 114. Ver además, en casos contenciosos, Caso de la Comunidad Indígena Yakye Axa; Caso de los Hermanos Gómez Paquiyauri, párr. 165; 146; Caso Juan Humberto Sánchez. Interpretación de la Sentencia sobre Excepciones Preliminares, Fondo y Reparaciones. (art. 67 Convención Americana sobre Derechos Humanos). Sentencia de 26 de noviembre de 2003. Serie C. No. 102, párr. 56; Caso de la Comunidad Mayagna (Sumo) Awas Tingni. Sentencia de 31 de agosto de 2001. Serie C No. 79, párrs. 146 a 148, y Caso Barrios Altos. Sentencia de 14 de marzo de 2001. Serie C No. 75, párrs. 41-44.

${ }^{69}$ Cfr. Caso Ricardo Canese Vs. Paraguay. Sentencia de 31 de agosto de 2004. Serie C No. 111, párr. 181; Caso Herrera Ulloa. Sentencia de 2 de julio de 2004. Serie C No. 107, párr. 184 y Caso Baena Ricardo y otros. Sentencia de 2 de febrero de 2001. Serie C No. 72.

70 Caso Dacosta Cadogán Vs. Barbados. Excepciones Preliminares, Fondo, Reparaciones y Costas. Sentencia de 24 de septiembre de 2009, Serie C, No. 204, párr. 49.

${ }^{71}$ Cfr. Caso 19 Comerciantes Vs. Colombia. Fondo, Reparaciones y Costas. Sentencia de 5 de julio de 2004. Serie C No. 109, párr. 173; Caso Boyce y otros, párr. 52, y Caso Trabajadores Cesados del Congreso (Aguado Alfaro y otros) Vs. Perú. Excepciones Preliminares, Fondo, Reparaciones y Costas. Sentencia de 24 de noviembre de 2006. Serie C No. 158, párr. 77.

72 Caso Hilaire, Constantine y Benjamin y otros, párr. 99, y Caso Raxcacó Reyes, párr. 56. Ver también Restricciones a la Pena de Muerte (arts. 4.2 y 4.4 Convención Americana sobre Derechos Humanos), párr. 57.

73 Cor IDH. Caso Furlán y Familiares Vs. Argentina. Excepciones Preliminares, Fondo, Reparaciones y Costas. Sentencia de 31 de agosto de 2013, Serie C, No. 246, párr. 123.

74 Artículo 126 del Código Civil de Argentina, antes de la reforma realizada por la Ley 26.579, sancionada el 2 de diciembre de 2009 (expediente de anexos al escrito de solicitudes y argumentos, tomo VII, folio 3154).

75 Cfr. Condición Jurídica y Derechos Humanos del Niño, dentro de la Opinión Consultiva OC-17/o2 del 28 de agosto de 2002. Serie A, No. 17, párr. 42. 
pretativo o norma de producción interna o externa, puesto que su finalidad es que prime aquella que mejor garantice o maximice el goce de un derecho fundamental.

\section{Criterios interpretativos del principio pro persona en México}

De acuerdo con Robert Alexy, los derechos fundamentales no pueden ser comprendidos de la sola lectura en la Constitución y afirma que resulta imperioso conocer su interpretación por parte de los tribunales. ${ }^{76}$ Es en este sentido que cobra relevancia aludir algunos casos que considero representativos en los que se ha hecho uso del principio pro persona, de manera que sea posible apreciar, de forma diversa, cómo es que las autoridades jurisdiccionales han aplicado e interpretado, de forma tanto progresiva como regresiva, dicho criterio hermenéutico que debiera informar todo el derecho en el campo de los derechos humanos.

\section{A. Contradicción de tesis $6 / 2008$}

Resulta importante hacer mención a la contradicción de tesis 6/2008 suscitada entre la Sala Superior del Tribunal Electoral del Poder Judicial de la Federación (SUP-JDC-85/2007) y la Primera Sala de la Suprema Corte de Justicia de la Nación (Contradicción de tesis 29/2007), en relación con la interpretación del artículo 38 constitucional fracción II. ${ }^{77} \mathrm{La}$ Sala Superior del Tribunal Electoral sostuvo una interpretación pro persona basada en el principio de presunción de inocencia, contenido en diversos tratados y convenciones internacionales aprobados por el Estado mexicano ${ }^{78}$ de manera que reconoció el derecho político de voto activo en las personas a quienes se dictara auto de formal prisión cuyo delito mereciera pena privativa de libertad pero no privadas de libertad. Por su parte, la Primera Sala de la Corte realizó una interpretación literal del artículo 38, de manera que desconoció el derecho al voto activo a cualquier persona sujeta a proceso penal a partir del auto de formal prisión, independientemente de que estuviera privada de su libertad o no. La SCJN resolvió la contradicción de tesis con base en el principio pro persona en su vertiente interpretativa, refiriendo que estaba en curso la iniciativa constitucional en materia de derechos humanos en la que se contenía expresamente ese principio en el artículo $1^{\circ}$ párrafo segundo y con base en el principio de presunción de inocencia, realizando una argumentación sustentada también en diversos instrumentos internacionales y cuyo rubro se expresó así: DERECHO AL VOTO. SE SUSPENDE POR EL DICTADO DEL AUTO DE FORMAL PRISIÓN O DE VINCULACIÓN A PROCESO, SÓLO CUANDO EL PROCESADO ESTÉ EFECTIVAMENTE PRIVADO DE SU LIBERTAD.

\footnotetext{
${ }^{76}$ Refiere que: "lo que hoy son los derechos fundamentales, es definido, principalmente, sobre la base de la jurisprudencia del Tribunal Constitucional Federal", la que se ha encargado de emitir precisiones que limitan el campo de posibilidades de los mismos, sin "restarle vivacidad", pero sin eliminar del todo la vaguedad." Cfr. ALEXY, Robert, Teoría de los Derechos Fundamentales, Centro de Estudios Constitucionales, Madrid, 2003, p. 23.

77 Artículo 38. Los derechos o prerrogativas de los ciudadanos se suspenden: ... II. Por estar sujeto a un proceso criminal por delito que merezca pena corporal, a contar desde la fecha del auto de formal prisión;...

78 Tales como la Declaración Universal de los Derechos Humanos, la Convención Americana sobre Derechos Humanos y el Pacto Internacional de Derechos Civiles y Políticos.
} 


\section{B. Expediente "Varios" 912/2010}

Este expediente resuelto por el Pleno de la SCJN, también conocido como el "Caso Radilla", abordó el principio pro persona en sus párrafos 27 y 35, estableciendo la obligatoriedad de todas las autoridades de la aplicación de la norma o la interpretación más favorable al derecho humano de que se trate, independientemente de si ésta se encuentra en la Constitución o en un tratado internacional del que México sea parte. ${ }^{79}$ En este expediente no se hizo referencia alguna a las restricciones o suspensiones en el ejercicio de los derechos humanos establecidas en la Constitución.

\section{Contradicción de tesis 293/2011}

En dicha contradicción suscitada entre el Primer Tribunal Colegiado en Materias Administrativa y de Trabajo del Décimo Primer Circuito y el Séptimo Tribunal Colegiado en Materia Civil del Primer Circuito, los temas a analizar fueron los siguientes: a) la determinación de "la posición, el lugar constitucional de los tratados internacionales en materia de derechos humanos, a partir de la reforma de junio de dos mil once, el contenido y alcance nuevo, del artículo $1^{\circ}$ constitucional" y en forma destacada, adquirió relevancia en el transcurso del debate, el tema sobre las restricciones constitucionales, y b) la obligatoriedad de las sentencias de la Corte Interamericana.

En virtud de que ambos temas inciden contundentemente en la comprensión del principio pro persona, y una vez analizados los debates desarrollados por los Ministros de la Corte, considero que el proyecto original presentado por el Ministro ponente, Arturo Zaldívar Lelo de Larrea, era el más adecuado si consideramos la definición aportada por Christian Courtis y Martín Ábrego, en la que establecen la doble dimensión que configura al principio pro persona mismo que se resume en estar siempre a favor de la persona.

Antes de referir las decisiones finales de la contradicción, considero de gran valía los argumentos expuestos por el Ministro Presidente Silva Meza, toda vez que menciona la importancia de mantener la congruencia con los criterios sostenidos por el máximo órgano del Poder Judicial en asuntos precedentes, tales como el expediente "Varios" 912/2010 y la Acción de inconstitucionalidad $155 / 2007,{ }^{80}$ en los que de manera mayoritaria se aplica y reconoce el principio pro persona y el rango constitucional de los tratados internacionales aprobados por el Estado mexicano que contengan derechos humanos. También destaco de su participación, el refrendo al proyecto original, en el que se configura al principio por persona como armonizador de las normas constitucionales y las contenidas en los tratados internacionales sobre derechos humanos, así como de los principios y valores ex constitutionae, en sentido

\footnotetext{
79 Véase Acuerdo del Tribunal Pleno de la Suprema Corte de Justicia de la Nación, correspondiente al día catorce de julio de dos mil once, para resolver el expediente "Varios" 912/2010.

${ }^{80}$ En dicha Acción que versa sobre la facultad de imposición de trabajos forzados por una autoridad administrativa en la legislación del Estado de Yucatán, la SCJN resolvió que el tratado protegía en mayor medida el derecho fundamental respecto de nuestra Constitución, de modo que se aplicó el principio pro persona y a su vez se da un reconocimiento al bloque de constitucionalidad entre Constitución y tratados internacionales en materia de derechos humanos. Por dicho motivo, la Ministra Luna Ramos solicitó que la Corte eliminara la referencia a la misma en la resolución de la Contradicción de tesis 293/2011 y se pronunció porque se considerara como criterio superado. Desde mi particular punto de vista, con dicha acción se está violando uno de los principios de los derechos fundamentales consistente en la progresividad -constitucionalizado en las reformas de junio de 2011-, que se caracteriza porque los logros y avances en materia de derechos humanos no podrán ser desconocidos ni tendrán carácter regresivo.
} 
amplio, y asumiendo el mandato del Constituyente Permanente, establecido a partir de las reformas de junio de 2011, de brindar la máxima protección de los derechos de las personas. Sostiene que: “...de llegarse a concluir que el texto escrito de la Constitución está por encima de los textos en que se expresan los tratados internacionales en materia de derechos humanos, la reforma no habría tenido sentido alguno."

En sesión del 3 de septiembre refirió que tratándose de restricciones a los derechos fundamentales, con base en el principio pro persona, deberán cubrir las siguientes condiciones: 1) Deberá ser por principio, excepcional, 2) Deberá acompañarse de una garantía, y 3) Deberá partir sobre la base de que la prevalencia de un derecho sobre otro será, siempre y cuando se garantice una mayor protección, de modo que será necesaria una ponderación.

Igualmente considero destacada la ponencia del Ministro Zaldívar en cuyo proyecto original refiere respecto del principio pro persona que debe quedar superada la jerarquía entre Constitución y tratados internacionales, puesto que a partir de la reforma al artículo $1^{\circ}$ constitucional, segundo párrafo, se mandata aplicar el principio pro persona en conjunto con los principios de universalidad, interdependencia, indivisibilidad y progresividad. Asimismo creo relevante la defensa de su postura respecto del principio pro persona, la cual refiere que debería prevalecer, ya sea que la mayor protección se encuentre en la Constitución o en los tratados internacionales de los que el país sea parte, y de igual manera si se trata de las restricciones a los derechos humanos. Dichos argumentos son, en lo personal, compartidos en su totalidad, sin embargo, el sentido de su voto al final de las diversas sesiones fue a favor del proyecto modificado en el que las restricciones al goce de un derecho fundamental se deben resolver de conformidad con lo establecido constitucionalmente, en lugar de estar conforme a la menor afectación al derecho en juego y de realizar una ponderación en cada caso.

Asimismo, en lo personal califico como digna y plausible la participación del Ministro José Ramón Cossío, quien mantuvo una línea discursiva y argumentativa sólida, de apoyo al proyecto original, por considerarlo congruente con la teleología del conjunto de reformas constitucionales en materia de derechos humanos, en la que de manera contundente sostiene que se da un cambio de paradigma y se configura una nueva antropología constitucional acorde con los compromisos internacionales asumidos por el Estado mexicano y en donde se coloca a las personas en el centro articulador del nuevo sistema mexicano. De ahí que fuera el único Ministro que sostuviera el respaldo al proyecto original y se apartara del criterio mayoritario de ir a favor del nuevo proyecto.

El Ministro Cossío Díaz fue el único que se pronunció por ubicar el debate en cuanto a la nueva conformación de la Constitución a partir de la reforma de junio de 2011, puesto que refirió que los colegiados no contaban con el marco constitucional actual por lo que sugirió que no se resolviera a favor de uno de los criterios, sino que se contextualizaran los temas a analizar de conformidad con las reformas. Y responde a la interrogante de por qué se separa del criterio mayoritario, diciendo que la jurisprudencia que se está construyendo por el Pleno se encuentra a favor de la Constitución, cuando debería dejarse a la decisión de los operadores jurídicos y que esta debería ser a favor de la "condición más favorable para efecto de los derechos", tal como se realizó en casos anteriores. Igualmente refiere que en virtud de que las reformas a los artículos $1^{\circ}$ y 29 constitucionales tuvieron la misma génesis, considera que las restricciones y suspensiones de los derechos fundamentales de las que habla el párra- 
fo primero in fine del artículo $1^{\circ}$, deberían entenderse referidas a lo dispuesto por el artículo $29 \mathrm{y}$ atender el mandato del principio pro persona en su plenitud. ${ }^{81}$

De igual manera, la Ministra Sánchez Cordero, en la sesión del 3 de septiembre de 2013, expuso en relación con el principio pro persona que al modificarse la Constitución en el sentido de reconocer los derechos humanos en vez de otorgarlos, las autoridades deberán realizar una actividad de armonización, complementariedad y maximización de los derechos -en atención al principio pro persona-, caso por caso, mediante el procedimiento que consideren más adecuado, como podría ser la ponderación y aplicando los criterios de razonabilidad y proporcionalidad, tomando en cuenta los principios de universalidad, interdependencia, indivisibilidad y progresividad característicos de los derechos humanos. ${ }^{82}$

Por otra parte, el criterio mayoritario, en relación con la posición de los tratados internacionales frente a la Constitución, si bien se definió por la igualdad de rango entre Constitución y tratados internacionales ratificados por el Estado mexicano, de forma personal considero que, en realidad se sostuvo la supremacía constitucional al establecer que tratándose de restricciones al ejercicio de un derecho humano, en lugar de aplicar el precepto o interpretación que menos perjuicio ocasione a la persona para el reconocimiento de un derecho fundamental, deberá aplicarse la disposición constitucional. De este modo, aprecio que el principio pro persona está siendo vulnerado y distorsionado en su dimensión negativa, consistente en la afectación menos lesiva en el goce del derecho humano en cuestión.

Al someter a votación el asunto resultaron diez votos a favor del proyecto modificado, con las diez reservas de formular sus respectivos votos, en la que se estableció como jurisprudencia obligatoria que los derechos humanos de fuente internacional tienen rango constitucional.

Solamente se emitió un voto en contra, proveniente del Ministro Cossío Díaz y la reserva de emitir su voto respectivo, quien en su última intervención en relación con este tópico profirió que:

...el principio pro persona, derivado de este mismo punto de vista, ya no es tan universal, el principio pro persona prevalecerá en aquellos casos en los que la Constitución lo haya determinado, que también es la posición de un número muy importante de los señores Ministros. Entonces, creo que es bastante -al menos para mí, y lo digo con mucho respeto- simple entender que si tengo por un lado derechos constitucionales, y del otro lado, tengo derechos convencionales, y van a prevalecer las restricciones, limitaciones que tengan los derechos constitucionales, el principio pro persona ya no juega como un equilibrador o como un universalizador si cabe esta expresión, sino tiene una posición prioritaria, ni siquiera lo de jerárquica respecto a los derechos convencionales.

En cuanto a la obligatoriedad de la jurisprudencia de la Cor IDH, el Ministro Zaldívar, previamente a consultar el sentido del voto del resto de ministros, señaló la importancia del Caso Gelman fallado por la Corte Interamericana, en cuanto a la obligatoriedad de la jurisprudencia para los Estados miembros, y por ende, la importancia de resolver internamente

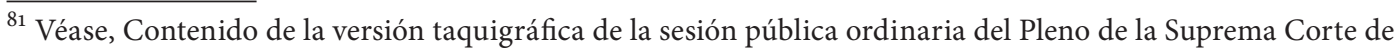
Justicia de la Nación, celebrada el 29 de agosto de 2013, correspondiente a la Contradicción de tesis 293/2011. 82 Ibidem, sesión del 3 de septiembre de 2013.
} 
en congruencia para procurar que los asuntos en materia de derechos humanos se atiendan en México y así evitar su posterior condena en una instancia internacional.

En apoyo a la solicitud del Ministro ponente se decidió someter a consideración la primera propuesta de tesis consistente en la obligatoriedad de la jurisprudencia de la Corte Interamericana, resultando una decisión de 6 votos a favor ${ }^{83}$ y 5 en contra. ${ }^{84}$ Como ya se ha expuesto, a partir del reconocimiento de la competencia contenciosa de la Cor IDH no es opcional el acatamiento de sus resoluciones ni de sus interpretaciones sino que son obligatorias por lo que resulta cuestionable el sometimiento a votación de dicho punto y consecuentemente su resultado.

Considero que la clave del abordaje de la controversia constitucional consiste en que los criterios divergentes se encontraban en un contexto de sistema jurídico vigente antes de las reformas de junio de 2011 y que los criterios que el Pleno de la Corte debió delinear y conformar tendrían que enmarcarse de conformidad con el nuevo paradigma constitucional establecido a raíz de tan significativas reformas y de las tendencias internacionales en materia de derechos humanos, cuestión a la que parecería no haber sido tan receptivo nuestro máximo órgano jurisdiccional a lo largo de las diversas sesiones de análisis, en ejercicio de las funciones de Tribunal Constitucional. Como además resolvió mayoritariamente que es obligatoria la jurisprudencia de la Corte Interamericana, concluyo que, en refrendo de lo expuesto por el Ministro Cossío, se arriba a una evidente contradicción entre las posibles restricciones de los derechos fundamentales en nuestro sistema jurídico nacional y los criterios de la Corte -que de manera general son más amplios y favorables-, los cuales en relación con el principio pro persona, de forma reiterada se ha pronunciado en el sentido de aplicar la norma o la interpretación más favorable independientemente del origen del precepto normativo. Considero que en su mayoría, no se entendió en su plena dimensión el sentido de un bloque de constitucionalidad conformado por la Constitución y los tratados internacionales sobre derechos humanos para la óptima aplicación del principio pro persona, tal como lo consagra el artículo $1^{\circ}$ constitucional.

A partir de la Décima Época de la SCJN ${ }^{85}$ originada precisamente con motivo de las reformas en materia amparo y de derechos humanos es posible constatar, en contraste con la Contradicción de tesis 293/2011, el cambio de paradigma constitucional sobre todo por parte de los tribunales federales, quienes aplican el principio pro persona con fundamento en el artículo $1^{\circ}$, párrafo segundo de la Constitución. Sin embargo es de destacarse que tanto la aplicación de la norma o de la interpretación más favorable a la persona, ha sido más protectora y acorde con el espíritu de las reformas por parte de los Tribunales Colegiados de Circuito y el Tribunal Electoral del Poder Judicial de la Federación, que respecto de la Suprema Corte. Y resulta notorio referirlo porque en los países en los que se cuentan con tribunales constitucionales al estilo kelseniano, son estos quienes marcan la pauta interpretativa más

\footnotetext{
${ }^{83}$ Emitidos por los Ministros Gutiérrez Ortiz Mena, Cossío Díaz, Zaldívar Lelo de Larrea, Valls Hernández, Sánchez Cordero y Silva Meza

${ }^{84}$ Correspondientes a los Ministros Luna Ramos, Franco González, Pardo Rebolledo, Aguilar Morales y Pérez Dayán.

${ }^{85}$ Integrada a partir del 4 de octubre de 2011 por Acuerdo General Número 9/2011, de 29 de agosto de 2011 del Pleno de la SCJN.
} 
progresista y protectora en materia de derechos humanos que el resto de los tribunales, cuando en México vemos, por lo general, resultados contrarios.

Tal lo podemos apreciar con la tesis de la Segunda Sala de la SCJN, de donde, si bien se desprende el reconocimiento del principio pro persona, no es posible interpretar con contundencia y claridad que sí se da un cambio de paradigma constitucional en favor de los derechos fundamentales:

PRINCIPIO PRO PERSONA O PRO HOMINE. FORMA EN QUE LOS ÓRGANOS JURISDICCIONALES NACIONALES DEBEN DESEMPEÑAR SUS ATRIBUCIONES Y FACULTADES A PARTIR DE LA REFORMA AL ARTÍCULO 10 . DE LA CONSTITUCIÓN POLÍTICA DE LOS ESTADOS UNIDOS MEXICANOS, PUBLICADA EN EL DIARIO OFICIAL DE LA FEDERACIÓN EL 10 DE JUNIO DE $2011 .{ }^{86}$ Si bien la reforma indicada implicó el cambio en el sistema jurídico mexicano en relación con los tratados de derechos humanos, así como con la interpretación más favorable a la persona al orden constitucional -principio pro persona o pro homine-, ello no implica que los órganos jurisdiccionales nacionales dejen de llevar a cabo sus atribuciones y facultades de impartir justicia en la forma en que venían desempeñándolas antes de la citada reforma, sino que dicho cambio sólo conlleva a que si en los instrumentos internacionales existe una protección más benéfica para la persona respecto de la institución jurídica que se analice, ésta se aplique, sin que tal circunstancia signifique que dejen de observarse los diversos principios constitucionales y legales que rigen su función jurisdiccional -legalidad, igualdad, seguridad jurídica, debido proceso, acceso efectivo a la justicia, cosa juzgada-, ya que de hacerlo se provocaría un estado de incertidumbre en los destinatarios de tal función.

Por otra parte, el Tercer Tribunal Colegiado del Décimo Octavo Circuito resolvió de forma más garantista al aplicar el principio pro persona, lo cual puede corroborarse en la tesis del rubro siguiente:

PRINCIPIO PRO HOMINE. SU CONCEPTUALIZACIÓN Y FUNDAMENTOS ${ }^{87}$... las normas en materia de derechos humanos se interpretarán de conformidad con la Carta Magna y con los tratados internacionales de la materia, procurando favorecer en todo tiempo a las personas con la aplicación más amplia. Dicho precepto recoge de manera directa el criterio o directriz hermenéutica denominada principio pro homine, el cual consiste en ponderar ante todo la fundamentalidad de los derechos humanos, a efecto de estar siempre a favor del hombre, lo que implica que debe acudirse a la norma más amplia o a la interpretación extensiva cuando se trate de derechos protegidos e, inversamente, a la norma o a la interpretación más restringida, cuando se trate de establecer límites para su ejercicio.

En esta misma línea argumentativa se pronunció otro Tribunal Colegiado estableciendo que si bien los artículos 156 del Código de Procedimientos Civiles para el Distrito Federal y 1.42., del Estado de México, en sus respectivas fracciones XII y XIII, disponen que en los juicios de divorcio es juez competente el del domicilio conyugal, tratándose de los juicios de alimentos,

\footnotetext{
$\overline{86}$ Tesis 2a. LXXXII/2012, Semanario Judicial de la Federación y su Gaceta, Décima Época, t. 2, noviembre de 2012, p. 1587.

87 Tesis XVIII.30.1 K, Semanario Judicial de la Federación y su Gaceta, Décima Época, t. 2, abril de 2012, p. 1838. 
podrá serlo el del domicilio del actor o del acreedor alimentario por tratarse de una acción privilegiada. Lo anterior encuentra sustento en los artículos $1^{\circ}$ y $4^{\circ}$ constitucionales que consagran los principios pro persona y de interés superior del menor respectivamente, así como en la Convención sobre los Derechos del Niño y la Convención Americana sobre Derechos Humanos, identificable bajo el siguiente rubro:

COMPETENCIA EN LOS JUICIOS DE DIVORCIO INCAUSADO Y ALIMENTOS. ATENDIENDO AL INTERÉS SUPERIOR DEL MENOR Y AL PRINCIPIO PRO HOMINE EN EL EXAMEN DE LOS DERECHOS HUMANOS, DEBE PREVALECER LA REGLA DE COMPETENCIA ESPECIAL A FAVOR DEL ACTOR O ACREEDOR ALIMENTARIO, SOBRE LA GENÉRICA QUE ATIENDE AL DOMICILIO CONYUGAL DE LOS DIVORCIANTES. ${ }^{88}$

\section{CONCLUSIONES}

La Segunda Guerra Mundial marca un parteaguas en el proceso de "internacionalización de los derechos humanos" en el que este tópico deja de ser competencia exclusiva de cada Estado, de ahí que producto del reconocimiento de los derechos humanos como del interés mundial se marca la pauta para una nueva forma de organización estatal, en la que el Estado constitucional y democrático de Derecho reformula que la vigencia de sus normas ya no son suficientes y que deben ir acompañadas de los elementos sustanciales que le dan legitimidad, racionalidad y significado, dentro de los cuales se encuentran los derechos fundamentales y sus garantías.

Estas condiciones de sustancialidad tienen por objetivo el brindar protección a los derechos fundamentales de las personas, incluso frente a decisiones de la mayoría, conformándose lo que en la doctrina se denomina "la esfera de lo indecidible" en donde se encuentran comprendidos los derechos fundamentales, cuyo fundamento esencial lo constituye la dignidad humana, de ahí la importancia de las respectivas garantías para su plena eficacia.

Es por lo anterior que los derechos fundamentales son considerados como elementos o principios esenciales del Estado constitucional en el cual se condensan los avances sustanciales del constitucionalismo, tales como los principios democráticos que reafirman el reconocimiento de la pluralidad y el respeto a los derechos de las minorías, lo cual no siempre puede darse en armonía, sin embargo, de esta manera es que se explica el nexo estructural entre el constitucionalismo y la democracia, en donde las garantías constitucionales de los derechos humanos son a la vez garantías de la democracia misma. El nuevo paradigma constitucional establecido a partir de las reformas constitucionales del diez de junio de 2011 establece nuevos retos a todas las autoridades, que van desde el conocimiento del nuevo corpus iuris, hasta su aplicación de manera armónica y con los instrumentos internacionales de los que México es parte y con la jurisprudencia de la Corte Interamericana de Derechos Humanos.

Es en este contexto que el principio pro persona adquiere relevancia puesto que constituye una garantía armonizadora, y más importante aún, maximizadora de la eficacia de los derechos fundamentales, puesto que dispone la aplicación de la norma o interpretación más amplia, cuando se trate de reconocer derechos, o bien, la norma o la interpretación más res-

\footnotetext{
${ }^{88}$ Tesis I.110.C.4 C, Semanario Judicial de la Federación y su Gaceta, Décima Época, t. 2, agosto de 2012, p. 1668.
} 
tringida cuando se esté en riesgo de afectar o limitar un derecho. De modo que su premisa fundamental consiste en estar siempre a favor de la persona.

Este principio además de estar previsto en el artículo $1^{\circ}$, segundo párrafo de la Constitución mexicana, ha sido interpretado por nuestras autoridades jurisdiccionales en ocasiones de forma adecuada, y en otras, de manera incorrecta -desde mi particular punto de vista-, de manera más precisa en cuanto se refiere a las restricciones o suspensiones de los derechos cuando se ha dispuesto que en lugar de estar de acuerdo con la norma que menos afecte un derecho, se establezca que deberá estarse conforme a lo dispuesto constitucionalmente, de modo que considero que se está desvirtuando la naturaleza de este principio. Esto acontece en la resolución de la Controversia Constitucional 293/2011, en la que excepcionalmente el Ministro Cossío Díaz vota en contra de esta interpretación constitucional.

No obstante lo anterior, existen resoluciones tanto de tribunales colegiados como de la Sala Superior del Tribunal Electoral del Poder Judicial de la Federación y de la Suprema Corte de Justicia de la Nación que permiten demostrar el gran avance que en materia de derechos humanos es posible, aún previo a la vigencia de las reformas de junio de 2011, siempre que se tenga la vocación y convicción de garantizar con mayor eficacia los derechos fundamentales, con sustento en una interpretación complementaria e integradora, es decir, de bloque de constitucionalidad entre la Constitución, los tratados internacionales sobre derechos humanos y la jurisprudencia de la Corte Interamericana de Derechos Humanos, tal como se ve reflejado en diversas experiencias de derecho comparado en Latinoamérica y en la misma Corte Interamericana.

\section{FUENTES}

BIBLIOGRÁFICAS

ALEXY, Robert, Teoría de los Derechos Fundamentales, Centro de Estudios Constitucionales, Madrid, 2003.

ALFONZO Jiménez, Armando, Acerca del Estado. Breves reflexiones sobre política y derecho, México, 2008.

ARMIJO, Gilbert, La tutela supraconstitucional de los derechos humanos en Costa Rica: http://www.scielo.cl/scielo.php?script=sci_arttext\&pid=So718$00122003000100005 \& \operatorname{lng}=$ en\& $n \mathrm{rm}=i$

BIDART Campos, Germán J., El derecho de la Constitución y su fuerza normativa, México, IIJ-UNAM, 2003.

BOVERO, Michelangelo, Los desafíos de la democracia, México, Ubijus, 2013.

CABALLERO Ochoa, José Luis, La incorporación de los tratados internacionales sobre derechos humanos en España y México, México, Porrúa, 2009.

- - - - - _ - (coord.), La Declaración Universal de los Derechos Humanos. Reflexiones en torno a su 60 aniversario, México, Porrúa, 2009.

CARBONELL, Miguel (ed.), Neoconstitucionalismo(s), 2 a ed., Madrid, Trotta, 2005. 
Cuadernos de Derecho Constitucional. Revista de la Maestría en Derecho Constitucional de la Universidad Latina de América, Morelia, Mich., vol. 1, no. 1, 2009.

FERRAJOLI, Luigi et al., La teoría del derecho en el paradigma constitucional, México, CAJICA, 2009.

-, Derechos y Garantías. La ley del más débil, Madrid, Trotta, 2004.

FIX-ZAMUDIO, Héctor, et. al., Protección internacional de los Derechos Humanos, Argentina, Librería Editora Platense, 2007.

GARCÍA RAMÍREZ, Sergio, Temas de la Jurisprudencia Interamericana sobre Derechos Humanos. Votos particulares, México, Instituto Tecnológico de Estudios Superiores de Occidente-Universidad Iberoamericana- Universidad Autónoma de Guanajuato, 2005.

HÄBERLE, Peter, El Estado Constitucional, México, UNAM, 2003.

- - _-_____- La garantía del contenido esencial de los derechos fundamentales en la Ley Fundamental de Bonn, trad. de Joaquín Brage Camazano, Madrid, Dykinson, 2003.

MENDEZ Silva, Ricardo (coord.), Derecho Internacional de los derechos humanos. Memoria del VII Congreso Iberoamericano de Derecho Constitucional, México, IIJ-UNAM, 2002.

MONTEMAYOR Romo de Vivar, Carlos, La unificación conceptual de los derechos humanos, México, Porrúa-Facultad de Derecho de la UNAM, 2002.

ORTIZ AHLF, Loretta et. al., Ensayos en torno a una propuesta de reforma constitucional en materia de política exterior y de derechos humanos, México, Porrúa-Universidad Iberoamericana, 2004 .

PRIETO Sanchís, Luis, Justicia constitucional y derechos fundamentales, Madrid, Trotta, 2003.

Propuesta de reforma constitucional en materia de derechos humanos, elaborada por las organizaciones de la sociedad civil y por académicas y académicos especialistas en derechos humanos, México, 2008 y disponible en: http://www.sumatealareformaendh. org. $m x$

REQUEJO Pagés, Juan Luis, Sistemas normativos, constitución y ordenamiento. La constitución como norma sobre aplicación de normas, Madrid, Mac Graw-Hill, 1995.

LEGISLACIÓN

Constitución Política de los Estados Unidos Mexicanos y Ley Federal para Prevenir y Eliminar la Discriminación. 
SENTENCIAS Y ACUERDOS

Acción de Inconstitucionalidad 155/2007; Acuerdo General No. 9/2011; Amparo en Revisión 1475/98; Expediente "varios" 912/2010; Contradicción de tesis 6/2008; Contradicción de tesis 293/2011, sesiones públicas ordinarias del Pleno de la Suprema Corte de Justicia de la Nación, versiones taquigráficas de 27 y 29 de agosto, 2 y 3 de septiembre de 2013 y Revisión de Amparo 799/2003.

Jurisprudencia y tesis

Tesis P. LXXVII/99, Semanario Judicial de la Federación y su Gaceta, Novena Época, t. X, noviembre de 1999, p. 46; Tesis 2a. LXXXII/2012, Semanario Judicial de la Federación y su Gaceta, Décima Época, t. 2, noviembre de 2012, p. 1587; Tesis I.11o.C.4 C, Semanario Judicial de la Federación y su Gaceta, Décima Época, t. 2, agosto de 2012, p. 1668 y Tesis XVIII.30.1 K, Semanario Judicial de la Federación y su Gaceta, Décima Época, t. 2, abril de 2012, p. 1838.

NORMATIVA INTERNACIONAL

Convención Americana sobre Derechos Humanos; Convención de Viena sobre el Derecho de los Tratados; Constitución Política de la República de Costa Rica; Declaración Universal de los Derechos Humanos y Pacto Internacional de Derechos Civiles y Políticos.

CASOS CONTENCIOSOS Y OPINIONES CONSULTIVAS DE LA COR ID

Caso 19 Comerciantes Vs. Colombia. Fondo, Reparaciones y Costas. Sentencia de 5 de julio de 2004. Serie C No. 109; Caso Baena Ricardo Vs Panamá. Fondo, Reparaciones y Costas. Sentencia de 2 de febrero de 2001, Serie C, No. 72; Caso Cabrera García y Montiel Flores vs. México. Excepciones preliminares, Fondo, Reparaciones y Costas. Sentencia de 26 de noviembre de 2010, Series C No. 220. Voto razonado del Juez Ad Hoc Eduardo Ferrer Mac-Gregor Poisot; Caso Dacosta Cadogán Vs. Barbados. Excepciones Preliminares, Fondo, Reparaciones y Costas. Sentencia de 24 de septiembre de 2009, Serie C, No. 204; Caso de la "Masacre de Mapiripán” Vs. Colombia. Fondo, Reparaciones y Costas. Sentencia de 15 de septiembre de 2005. Serie C. No. 134; Caso Furlán y Familiares Vs. Argentina. Excepciones Preliminares, Fondo, Reparaciones y Costas. Sentencia de 31 de agosto de 2013, Serie C, No. 246; Caso Gelman vs. Uruguay, Supervisión de cumplimiento de sentencia de 20 de marzo de 2013, Voto razonado del Dr. Eduardo Ferrer Mac-Gregor Poisot; Caso Herrera Ulloa Vs. Costa Rica, Sentencia de 2 de julio de 2004. Serie C No. 107; Caso Ricardo Canese Vs. Paraguay, Sentencia de 31 de agosto de 2004. Serie C No. 111; Caso Radilla Pacheco Vs. México, Excepciones Preliminares, Fondo, Reparaciones y Costas, Sentencia de 23 de noviembre de 2009, Serie C No. 209; Opinión Consultiva OC-16/99 de 1 de octubre de 1999, Serie A No. 16; Opinión Consultiva OC-17/02 del 28 de agosto de 2002. Serie A No. 17 y Opinión consultiva solicitada por el Perú el 24 de septiembre de 1982, disponible en: http://www.acnur.org/biblioteca/pdf/1263.pdf 